\title{
MEASUREMENTS AND MODELING OF ENVIRONMENTAL TOBACCO SMOKE LEAKAGE FROM A SIMULATED SMOKING ROOM
}

\author{
J Wagner ${ }^{1}$, DP Sullivan ${ }^{2}$, D Faulkner ${ }^{2}$, LA Gundel $^{2}$, WJ Fisk $^{2}$, LE Alevantis ${ }^{1}$, and JM \\ Waldman ${ }^{1}$ \\ ${ }^{1}$ Environmental Health Laboratory, California Dept. of Health Services, Berkeley, CA, USA \\ ${ }^{2}$ Indoor Environment Dept., Lawrence Berkeley National Laboratory, Berkeley, CA, USA
}

\begin{abstract}
The purpose of this study is to quantify the effect of various design and operating parameters on smoking room performance. Twenty-eight experiments were conducted in a simulated smoking room with a smoking machine and an automatic door opener. Measurements were made of air flows, pressures, temperatures, two particle-phase ETS tracers, two gas-phase ETS tracers, and sulfur hexafluoride. Quantification of leakage flows, the effect of these leaks on smoking room performance and non-smoker exposure, and the relative importance of each leakage mechanism are presented. The results indicate that the first priority for an effective smoking room is to depressurize it with respect to adjoining non-smoking areas. Another important ETS leakage mechanism is the pumping action of the smoking room door.

Substituting a sliding door for a standard swing-type door reduced this source of ETS leakage significantly. Measured results correlated well with model predictions $\left(\mathrm{R}^{2}=0.82-0.99\right)$.
\end{abstract}

\section{INDEX TERMS}

Environmental tobacco smoke, Ventilation, Chamber studies, Nicotine, Smoking room.

\section{INTRODUCTION}

The objective of this work was to quantify environmental tobacco smoke (ETS) leakage as a function of various smoking room operating and design parameters and measure its impact on performance. Smoking room performance was measured by releasing sulfur hexafluoride $\left(\mathrm{SF}_{6}\right)$ in a manner that simulated ETS generation. In some cases, however, the dynamics and transport of the various ETS components can differ substantially from that of $\mathrm{SF}_{6}$ (Alevantis et al., 1994) and from each other (Daisey, 1999). To address this issue, four particle- and gasphase ETS tracers were measured in a subset of the tests.

Three potential ETS leakage mechanisms were investigated: (a) leakage through wall cracks or the gap under the door when the smoking room is pressurized relative to the non-smoking area; (b) leakage via the pumping action of the door as occupants enter and leave the smoking room; and (c) leakage through the overhead ceiling plenum. If the plenum above the smoking room is not isolated from the adjoining space's plenum, ETS can leak into the shared plenum. If ventilation systems for the non-smoking areas draw return air from the plenum, ETS can be recirculated into these areas. Keeping the smoking room depressurized relative to the overhead plenum will minimize leakage when the door is closed. Whenever the door opens, however, the smoking room pressure will quickly equilibrate with that of the nonsmoking area and become higher than that of the plenum. This situation, while improved, can

\footnotetext{
*Contact author email: jwagner@dhs.ca.gov
} 
still result in sporadic bursts of ETS into the overhead plenum.

The impact of these leakage mechanisms on smoking room effectiveness was assessed using two performance measures: smoking room exhaust efficiency and protection factor. The smoking room exhaust efficiency is the percentage of smoking room ETS that is successfully removed by the exhaust to the outdoors. The remainder can be assumed to escape from the smoking room into the surrounding, non-smoking areas. The steady-state exhaust efficiency, $\eta_{\text {exh }}$, is given by

$$
\eta_{\text {exh }}=Q_{\text {exh, SR }}[E T S]_{S R} / S \quad \mathrm{x} 100 \%
$$

where $Q_{\text {exh, } S R}$ is the smoking room exhaust flow, $[E T S]_{S R}$ is the ETS concentration in the smoking room exhaust duct at steady-state, and $S$ is the generation rate of ETS. In these experiments, $\mathrm{SF}_{6}$ was released into the smoking room alongside the smoked cigarettes. $\mathrm{SF}_{6}$ was injected at a known value of $S$ and was thus a convenient, inert tracer for ETS leakage.

We have devised a new parameter, the smoking room protection factor $(S R P F)$. SRPF represents the reduction in ETS concentration in non-smoking areas relative to the hypothetical case with no smoking room protection:

$$
S R P F=[E T S]_{N S R, \text { no SR }} /[E T S]_{N S R}=\left(S / Q_{\text {out }, N S R}\right) /[E T S]_{N S R}
$$

where $[E T S]_{N S R}$ is the measured non-smoking room ETS concentration when a smoking room is used, $[E T S]_{N S R \text {, no } S R}$ is the non-smoking room ETS concentration that would have resulted from not using a smoking room (i.e., smoking in the same space as the non-smokers), and $\mathrm{Q}_{\text {out }}$ NSR is the total flow out of the non-smoking area. For example, a measured SRPF value of 20 means that ETS concentrations in the non-smoking area are 20 times lower than they would have been if a smoking room had not been in operation. $\mathrm{SF}_{6}$ was used as a tracer for ETS when calculating $S R P F$ values.

Two particle-phase ETS tracers were measured: total particulate matter (PM) concentration and optical absorption of PM at 370nm (UVPM). UVPM has been found to be a sensitive and unique tracer of ETS (Gundel et al., 2000). Two gas-phase ETS tracers were measured: nicotine and 3-EP.

\section{METHODS}

An existing chamber at Lawrence Berkeley National Laboratory (LBNL) was modified so that it consisted of two rooms separated by a wall with a door. The gap under the door was $0.64 \mathrm{~cm}$. The two rooms were designated as the smoking room (SR) and non-smoking room (NSR), respectively. A suspended ceiling created a shared, $22.9 \mathrm{~cm}$-high plenum above both rooms. The ceiling panels were of a common, "slag wool" (synthetic vitreous fiber) variety, and were cut to fit the lattice so that no gaps were visible. For the experiments with no shared plenum, the ceiling panels were removed and the plenum spaces above the two rooms were separated with a silicone-rubber-sealed acrylic divider.

Each room had a separate HVAC system. The supply air for each room passed through a high-efficiency filter, chiller coil, temperature-controlled duct heater, and a diffuser grille. SR air was exhausted to the outside. A fraction of the NSR exhaust airstream was returned to the NSR supply via a recirculation fan, and the remainder was exhausted to the outside. By adjusting the recirculation, supply, and return flows with regulating valves, a wide variety of 
pressure differences could be created between the SR, NSR, and ceiling plenum. The SR was equipped with an automated, programmable smoking machine built at LBNL. The smoking machine could smoke 16 cigarettes consecutively. One cigarette was smoked at a time. A computer system controlled the smoking machine, a pneumatic-piston-based door-opening mechanism, and four rotating mixing fans. A door "open/close" cycle was initiated immediately before a cigarette was smoked and immediately afterwards, simulating a smoker entering and leaving the SR. $\mathrm{SF}_{6}$ was released adjacent to the smoking machine.

Duct air flow rates, temperatures, and pressures were monitored using a data acquisition system. $\mathrm{SF}_{6}$ was measured at 9 locations using 2 gas chromatographs with electron capture detectors and automated, multiport samplers. PM concentrations were determined gravimetrically using filter cassettes. ASTM Method \#D5075-96 (ASTM, 1998) was used to determine gas-phase nicotine and 3-EP concentrations. Two dual-channel aethalometers were used to monitor UVPM in the NSR and NSR supply air.

Unless noted otherwise, each test typically lasted 4.5 hours, with 1.5 hours allowed for achieving steady-state chamber concentrations. The real-time samplers were used over the entire 4.5 hours, while the integrated samplers were operated for the last 3 hours of steadystate conditions only. Four sets of experiments were performed:

1) Leakage under closed door. These tests were conducted with the door closed and with no shared overhead plenum. Three positive values of the pressure gradient between SR and NSR were investigated, $\Delta P_{S R}=P_{S R}-P_{N S R}=0,2.5$, and $5 \mathrm{~Pa}$.

2) Leakage via door pumping. These experiments lasted less than an hour and did not use a shared overhead plenum. The gap under the door was filled, the ventilation system was turned off, and $\Delta P_{S R}=0$. In each test, $\mathrm{SF}_{6}$ was allowed to build up in the $\mathrm{SR}$ with the door closed. After the injector was turned off, one door open/close cycle was performed, causing a burst of $\mathrm{SF}_{6}$ to be pumped into the NSR. Tests were conducted using three different temperature gradients between rooms, $\Delta T_{S R}=T_{S R}-T_{N S R}=2,0$, and $-2{ }^{\circ} \mathrm{C}$. In addition to three tests with a swing-type door, one test was performed with a sliding door.

3) Leakage under door and via door pumping. In these tests, a swing-type door was opened on a regular schedule but was closed the remainder of the time, so ETS could leak both under the door and via door pumping. The major variable of these tests was $\Delta P_{S R}$, which ranged from -10 to $+5 \mathrm{~Pa}$. These tests were performed using two different door-opening rates: 8 and 13.3 door cycles per hour (corresponding to 4 and 6.67 cigarettes per hour). In addition, two different $\Delta T_{S R}$ values were investigated: $0{ }^{\circ} \mathrm{C}$ and $2{ }^{\circ} \mathrm{C}$.

4) Leakage through shared ceiling plenum. These tests were performed with the overhead plenum open between the SR and NSR and minimal pressure difference between rooms. All but one of these tests were performed with the door closed. Four positive values of pressure difference between SR and ceiling plenum were investigated, $\Delta P_{c p}=P_{S R}-P_{c p}=$ $0,0.3,0.8$, and $2 \mathrm{~Pa}$. In addition, the effect of varying the SR exhaust airflow at one of these plenum pressures was studied. Finally, one test was performed in which the door opened 8 times/hour. During this test, the SR pressure was only higher than the plenum when the door opened.

One additional test was performed to investigate, within the limits of the test facility, the performance of a "no door" smoking room with high ventilation. In all, 27 experiments plus 5 replicates were performed. Cigarettes were smoked and ETS tracers were sampled in 9 of these tests plus 2 of the duplicates. Ventilation flow rates ranged from 0-100 L/s, corresponding to a ventilation range of $0-14.6 \mathrm{ACH}$ and $0-9.8 \mathrm{~L} / \mathrm{s} /\left(\mathrm{m}^{2}\right.$ floor area). 


\section{RESULTS}

Smoking room leakage flows were determined for each experiment set using $\mathrm{SF}_{6}$ mass balances. A least squares fit to the data from Experiment Set 1 produced the equation:

$$
Q_{\text {under door }}=6.10\left(\Delta P_{S R}\right)^{0.573}
$$

where $Q_{\text {under door }}$ is the flow under the door in units of $\mathrm{L} / \mathrm{s}$ and $\Delta P_{S R}$ is in $\mathrm{Pa}$.

The volume of air pumped by the door, $V_{\text {door pump }}$, was determined in Experiment Set 2 . The average $V_{\text {door pump }}$ for the three swing-type-door tests was $672 \mathrm{~L}$, with no apparent dependence on $\Delta T_{S R}$. For the sliding door, $V_{\text {door pump }}=152 \mathrm{~L}$. The equivalent $Q_{\text {door pump }}$ is then

$$
Q_{\text {door pump }}=D V_{\text {door pump }}
$$

where $D=$ number of door cycles / time.

A least squares fit to the data from Experiment Set 4 produced the equation

$$
Q_{S R-c p}=28.5\left(\Delta P_{c p}\right)^{0.484}
$$

where $Q_{S R-c p}$ is the flow from the SR into the ceiling plenum in units of $\mathrm{L} / \mathrm{s}$ and $\Delta P_{c p}$ is in $\mathrm{Pa}$. Then, the effective flow for a plenum leak that occurs only when the door opens is

$$
Q_{S R-c p, \text { open door only }}=\quad D \tau_{\text {door }} Q_{S R-c p}
$$

where $\tau_{\text {door }}$ is the average time the door is open per cycle.

The leakage flows calculated with Equations 3 - 6 are plotted together on Figure 1 as a function of the pressure drop across the appropriate boundary. The plot assumes a swing-type

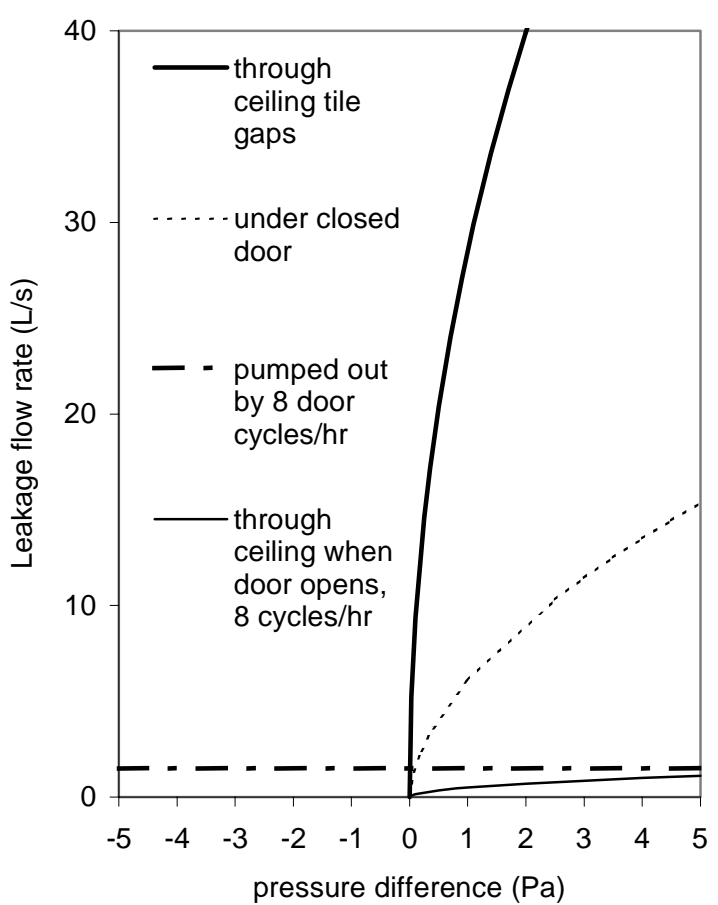

Figure 1. Comparison of SR leakage flows.

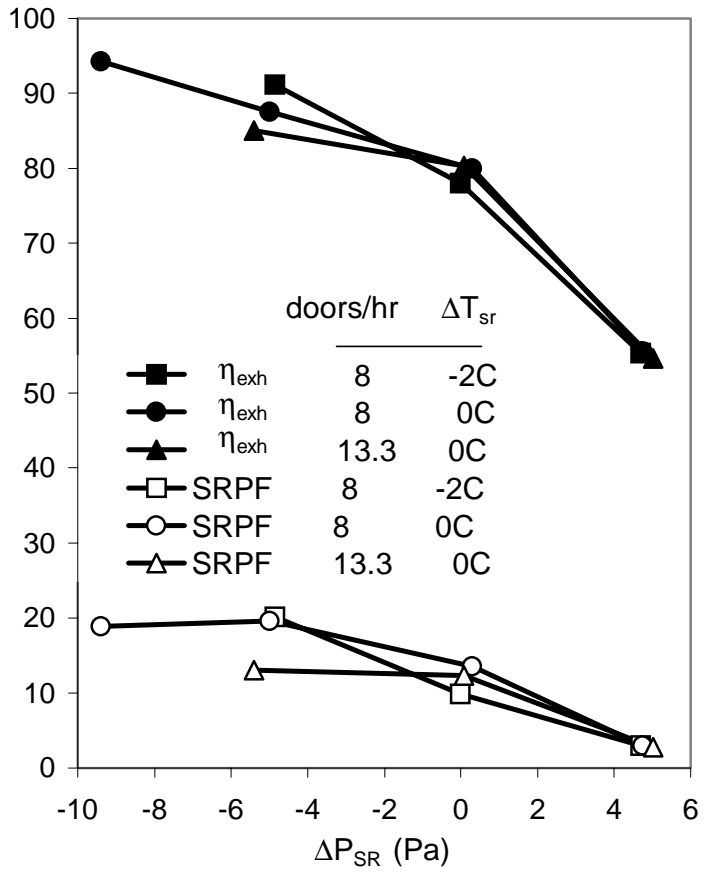

Figure 2. SR performance vs. pressure gradient. 
door, $D=8$ door cycles/hour and 8 s/door opening. Assuming that $\Delta P_{S R}$ and $\Delta P_{c p}$ typically range within the same order of magnitude as each other, this plot can be used to determine the most important leakage mechanism in a given situation.

Steady-state $\eta_{\text {exh }}$ and SRPF values were determined using Equations 1 and 2 . Measured $\eta_{\text {exh }}$ values ranged from 0-94\%. Measured $S R P F$ values ranged from $1.2-98$. Figure 2 is a plot of $\eta_{\text {exh }}$ and $S R P F$ values measured in Experiment Set 3 as a function of $\Delta P_{S R}$. Curves are plotted for $\Delta T_{S R}=0$ and $-2{ }^{\circ} \mathrm{C}$ at ( 8 door cycles per hour) and for $D=13.3$ door cycles per hour $\left(\Delta T_{S R}\right.$ $=0)$. The $\eta_{\text {exh }}$ and $S R P F$ curves in Figure 2 correspond to a SR exhaust rate of $26.5 \mathrm{~L} / \mathrm{s}$. These results can be generalized to different building sizes and nonsmoking-area ventilation rates, as $\eta_{\text {exh }}$ and SRPF do not depend upon $Q_{e x h}$, NSR. Figure 2 shows that both $\eta_{\text {exh }}$ and $S R P F$ were generally high when the SR was depressurized relative to the NSR, but decreased sharply as it became pressurized. Figure 2 also reveals that a temperature difference of $2{ }^{\circ} \mathrm{C}$ did not produce a measurable effect. Increasing the number of door cycles per hour did decrease $\eta_{\text {exh }}$ and $S R P F$, but only when the SR was depressurized and door pumping was the dominant mechanism. Experiment Set 4 showed similar trends, with $\eta_{\text {exh }}$ and $S R P F$ decreasing as the SR became more pressurized with respect to the plenum. Increasing the SR exhaust flow rate was found to cause substantial improvements in $\eta_{\text {exh }}$ and $S R P F$. Although increased SR exhaust flow does not prevent the various ETS leakage mechanisms from occurring, it does lower the ETS concentration in the SR, effectively reducing the strength of the leakage source.

Mass balances were performed for 23 of the tests to model $\eta_{\text {exh }}$ and $S R P F$ as a function of chamber pressures and exhaust flows. Correlation between modeled and measured results was high $\left(\mathrm{R}^{2}=0.99\right.$ and 0.83 for $\eta_{\text {exh }}$ and $S R P F$, respectively).

In the NSR, correlations between the four ETS tracers and $\mathrm{SF}_{6}$ ranged from $0.79-0.99$. In the $\mathrm{SR}$, the correlations ranged from $0.06-0.83$. Exposure ratios $\left(=[\mathrm{ETS}]_{\mathrm{NSR}} /[\mathrm{ETS}]_{\mathrm{SR}}\right)$ were calculated for each tracer as well. On average, exposure ratios calculated with 3-EP, PM, and nicotine were $34 \%, 41 \%$, and $91 \%$ lower than those calculated with $\mathrm{SF}_{6}$, respectively.

\section{DISCUSSION}

Equations 3 - 6 are useful for predicting SR leakage flows in actual buildings, as the inputs are relatively easy to obtain. The $\Delta P$ exponents in Equations 3 and 5 are both nearly equal to 0.5 , which agrees well with the standard relationship for flow through an orifice. It should be noted, however, that these equations would have different coefficients for smoking room doors and ceiling panel configurations substantially different than the ones tested. For example, replacing some of the SR ceiling panels with grilles increased the leakage area substantially. These increases simultaneously reduced the pressure drop across the ceiling and increased the leakage flow. As a result, a suspended ceiling with several panels missing would likely have a very low pressure drop across the ceiling, but a substantially higher leakage flow than that predicted by Equation 5. Gaps under real-world smoking room doors vary as well, though to a lesser degree.

The pumping action when the door opens may have an enhanced impact on occupants of spaces immediately adjacent to the smoking room. The $V_{\text {door pump }}$ measured here for the swing-type door was $38 \%$ of the volume swept by door as it opened and closed. This value compares reasonably well the work of Kiel and Wilson (1989), who reported typical values of about $50 \%$. The use of a sliding door instead of a conventional door is a promising method to 
reduce this leakage mechanism. In the tested configuration, using the sliding door reduced ETS leakage via door pumping by $77 \%$. Hypothetically, the use of a SR with no door could completely eliminate this ETS leakage source. However, thermally-induced circulations in our "no door" test caused NSR ETS levels to be not much lower than the case with no smoking room at all $(S R P F=2.4)$. Leakage through the ceiling plenum that occurs only when the door opens was observed to be a relatively minor leakage mechanism. Nevertheless, this mechanism can be eliminated by isolating the SR from the non-smoking area's ceiling plenum with a sealed wall.

Correlation between $\mathrm{SF}_{6}$ and the ETS tracers was very good in the NSR, but poor in the SR. High nicotine and 3-EP levels in the SR likely caused significant sorption onto SR walls. Reemission of these compounds on subsequent experiment days probably led to elevated air concentrations, even during experiments when $\mathrm{PM}$ and $\mathrm{SF}_{6}$ emissions were low. Despite generally good correlation, the ETS tracers exhibited lower exposure ratios than $\mathrm{SF}_{6}$, implying lower leakage to the NSR. Reduced PM exposure ratios may be partially due to differing semivolatile particle evaporation rates from the SR and NSR filters, which used two different sampling flow rates. Low nicotine exposure ratios are likely due to sorption of nicotine onto SR and NSR surfaces. The higher 3-EP exposure ratios are consistent with this interpretation, as 3-EP is more volatile and less sorptive than nicotine.

\section{CONCLUSION AND IMPLICATIONS}

ETS leakage flows have been quantified as a function of various operating and design parameters in a controlled chamber. Measured results correlated well with results modeled with simple mass-balance equations. This information can provide guidance for effective smoking room design and operation. The results indicate that the first priority for an effective smoking room is to depressurize it with respect to adjoining non-smoking areas. If this goal is achieved, the next most significant ETS leakage mechanism is the pumping action of the smoking room door when it is opened and closed. Substituting a sliding door for a swingtype door reduced this source of ETS leakage by 77\%. The "no door" configuration tested in this study resulted in only modest non-smoker protection.

Although the relative importance of the various leakage mechanisms was determined with $\mathrm{SF}_{6}$, correlation between the ETS tracers and $\mathrm{SF}_{6}$ was generally good $\left(\mathrm{R}^{2}>0.8\right.$ in the NSR). Thus, these conclusions should apply to leakage of the ETS tracers as well. However, the magnitude of all the leakage mechanisms would be somewhat less for 3-EP and PM and substantially less for nicotine.

\section{ACKNOWLEDGMENTS}

This work was supported by funds from the California Tobacco-Related Disease Research Program, Grant Numbers 8RT-0157 and 8RT-0157S, and by the Assistant Secretary of Conservation and Renewable Energy, Office of Building Technologies, Building Systems and Materials Division. 


\section{REFERENCES}

Alevantis LE, Liu K-S, Hayward SB, et al. 1994. Effectiveness of ventilation in 23 designated smoking areas in California office buildings. Proceedings of the American Society of Heating, Refrigerating, and Air Conditioning Engineers IAQ'94 Conf., pp 89-103.

ASTM, 1998. D5075-96, Standard test method for nicotine and 3-ethenylpyridine in indoor air. West Conshohocken, PA: American Society for Testing and Materials.

Daisey J.M. 1999. Tracers for assessing exposure to environmental tobacco smoke: what are they tracing? Environmental Health Perspectives. Vol. 107 (suppl 2), pp 319-327.

Gundel LA, Shpilberg VE, Sullivan DP, et al. 2000. Real-time monitoring of dilute environmental tobacco smoke in the presence of other particle sources. Presented at 10th Annual ISEA Conference, Monterey Peninsula, California.

Kiel DE and Wilson DJ. 1989. Combining door swing pumping with density driven flow. ASHRAE Transactions. Vol. 95(2), pp 590-599. 